\title{
Looking back on 2019: a selection of Food Security articles
}

\author{
Serge Savary ${ }^{1}$
}

Published online: 17 January 2020

(C) International Society for Plant Pathology and Springer Nature B.V. 2020

\begin{abstract}
Food Security has a multidisciplinary vision which addresses all the dimensions of food security at all its scales, from the individual to global. The journal involves a large Editorial Board and an extended network of Reviewers. Nevertheless, because of the many dimensions of the food security problem, because of the large size of the submissions that are commonly submitted to the journal, and because of our aim to excellence, publication may sometimes be slow. We shall do better in 2020. This editorial highlights some of the diversity, relevance, and importance of Food Security as an international scientific journal in different fields: the importance of sociology and social capital; the physical access to food; agriculture - what it is supposed to deliver as a system and its sustainability; gender and the inequality of gender towards food; and the environmental constraints to achieving food security. Some Food Security submissions involve up to three Editors and ten Reviewers to achieve publication: This Editorial is also meant to thank the very large, volunteer, community involved in Food Security: Authors, Editors, and Reviewers.
\end{abstract}

The year 2019 brought about a landmark publication in the field of food security. This is a report published in the Lancet (Willett et al. 2019), which addresses the nexus of relations between climate, ecology, agronomy, population growth, medicine, and nutrition and food, globally. The 45-pages publication thus addresses a series of major connected problems, and yet, yields simple and essential conclusions: human nutrition is the main cause for global changes (including climate and biodiversity); and nutrition is a key entry point to simultaneously addresses the current environmental crises. This is an important article for the Food Security readership, as well as its Authors, Reviewers, and Editors, for two sets of reasons. One is the size of the work, the framework of thoughts it offers, and the importance of its conclusions. And the other is the shape of Lancet report which in many ways echoes the multi-disciplinary scope of Food Security.

Food Security wants to address the issue of food security in all its dimensions, and therefore, tries to mobilise all the disciplinary fields of science that can help assess, understand, and provide answers to food (in)security. The journal does so across ecoregions in the world; it tries to not have a bias towards a given set of systems or contexts, and looks at urban

Serge Savary

serge.savary@inra.fr

1 Institut National de la Recherche Agronomique, INRA, Auzeville, France and rural settings, at the global South as well as the global North. The journal, also, publishes articles that are sometimes very large. And Food Security tries its best to achieve academic excellence. Because of its inter-disciplinary view, because of the wide range of methods used by our Authors, because of the size of some of the submissions we receive, the journal is admittedly slow. While it is commonplace at Food Security to see submissions published in the following six months, some submissions can take up to two years, up to six successive reviews, the contribution of up to six Reviewers, and the involvement of up to three members of the Editorial Board to lead to a printed outcome. Very few scientific journals do that today. Instead on betting on speed and fast turnover, we try to invest in time, relevance, and scientific quality.

What follows is not a selection of the "best" articles published in Food Security in 2019 - I cannot judge that, and I have no means to do so. Instead, I have selected a small set of articles which are illustrative of the diversity of publications in Food Security, and also of the work which has been invested in the Journal by Editors, Reviewers, and Authors. This editorial is a way to thank them all.

Sociology and the social capital are important angles to address food security. In her article on household composition and food security in Nigeria, Esther Lamidi (2019) demonstrates that higher risks of severe food insecurity occurs among households with children and those with elderly persons living with a disability: the intrinsically most 
vulnerable elements of society, children and the elderly, are also surrounded by the highest risks. Sadly, the study also shows that financial support from friends, relatives, and money lenders was associated with higher, rather than lower, risks of food insecurity: in some conditions, the very functioning of the social capital cannot operate properly as a safety net. In these conditions (Lamidi 2019), intervention programs should target households with children and those with elderly persons living with disabilities. In their study in the USA, Wang and Bishop (2019) report, by contrast, that older adults with greater social strain and lower emotional support were at increased risk of food insecurity. In the context of this study, the social capital works properly - not (or not necessarily) in terms of money, but through moral and emotional support: love and affection do matter in combatting food insecurity.

The physical access to food is one critical, yet poorly documented component of food security. In a rare and exceptionally well-documented study using high-resolution spatial information and agent-based modelling, Koh et al. (2019) address this question in Columbus, Ohio (USA). They simulate food shopping patterns of households based on the actual location of homes and food stores, transportation network, household income, vehicle ownership, and distance to food stores. The study brings about recommendation at the local level of how, for example, to distribute food stores (and which food stores) in a neighbourhood. This is a fine example of research towards policy at the very local scale. This article will hopefully encourage more work in this area.

Agriculture, what it is supposed to do and deliver, and the general interconnected issues of agricultural performances, ecosystem services, and sustainability is a mainstay of the literature on food security, including at Food Security. The journal has, as in the previous years, published many articles on field crops. It also has addressed important other types of food production systems. Household gardens are critical in ensuring sustained and diverse food to households along with their roles on gender, generation-binding, biodiversity, and culture. Integrated interventions on home gardens combine training in gardening practices with education about nutrition knowledge. In their study in Bangladesh, Baliki et al. (2019) provide evidence for their long-term impact, and show that micronutrient supply for iron, zinc, folate and pro-vitamin A from home gardens was maintained in the longterm. In a study on homestead fishpond, also in Bangladesh, Ahmed and Waibel (2019) show that homestead aquaculture increases household food consumption and improves dietary diversity; it generates additional income and stimulates higher fish consumption from home production. Home food production for and by the poor is often undervalued by governments and should be better recognised through specific policies, including extension. The seed systems for roots, tubers, and banana collectively represent an example of poorly supported and insufficiently recognized element of key agricultural systems of the Global South. The analysis by Almekinders et al. (2019) considers potato, sweet potato, cassava, yam, and banana. The local seed systems are adapted and dynamic, reflecting farmers' agricultural and social contexts. This study demonstrates that a better understanding of farmers' needs underpinning these dynamics is a necessary condition for prioritizing investments to increase the use of improved seed by smallholder farmers. Another example in this theme is the report by Falkowski et al. (2019) on the Lacandon Maya milpa. This article brings a fresh look at the nutritional value, the cultural significance and the environmental meaning of maize, from the perspective of farmers who invented a crop now cultivated all over the world, form many purposes other than food.

Gender in relation to food security is not sufficiently addressed in the food security literature. An exceptionally detailed and documented analysis concerns India, a country where over half of all women of reproductive age are affected by anaemia has been published by Soumya Gupta et al. (2019). The study demonstrates that women's empowerment in agriculture will improve women's nutrition: women who are empowered in their agricultural decisions have significantly higher dietary diversity scores relative to women who are disempowered of such decisions. This work highlights the importance of reorienting India's agricultural price and procurement policies beyond staple grains to ensure better dietary diversity.

\section{The environmental constraints to food production,} climate change in particular, does not unfortunately constitute a very important theme in Food Security, despite its acute importance today. We have nevertheless published articles on the topic. One example is the study by Sileshi et al. (2019) on the adoption of soil and water conservation strategies in Eastern Ethiopia. This work shows that the adoption of soil and water conservation methods increases the per capita food consumption expenditure and net crop value; it also is significantly associated with a reduction in the probability of farmers being food insecure in the short and long terms, and vulnerable to food insecurity. Another example is the very detailed analysis by Souissi et al. (2019) on the water foot print of food security in Tunisia, where the average water footprint for the main consumed food groups has increased by $31 \%$ during recent decades, from $1208 \mathrm{~m} 3 /$ capita/year in 1985 to $1586 \mathrm{~m} 3 / \mathrm{capita} /$ year in 2010 . While the consumption in cereals has declined during this period, the consumption of animal products has increased. The study also shows that the water footprints of urban diets are significantly higher than those of rural diets, reflecting the difference in standards of living. The current food consumption trends will therefore 
increase the pressure on very limited water resources, especially in Tunis and the coastal areas of Tunisia, calling for a number of actions to take, from policies, to technologies and to education of the public.

\section{References}

Ahmed, B. N., \& Waibel, H. (2019). The role of homestead fish ponds for household nutrition security in Bangladesh. Food Security, 11, 835854.

Almekinders, C. J., Walsh, S., Jacobsen, K. S., Andrade-Piedra, J. L., McEwan, M. A., de Haan, S., Kumar, L., \& Staver, C. (2019). Why interventions in the seed systems of roots, tubers and bananas crops do not reach their full potential. Food Security, 11, 23-42.

Baliki, G., Brück, T., Schreinemachers, P., \& Uddin, M. N. (2019). Longterm behavioural impact of an integrated home garden intervention: Evidence from Bangladesh. Food Security, 11, 1217-1230.

Falkowski, T. B., Chankin, A., Diemont, S. A., \& Pedian, R. W. (2019). More than just corn and calories: A comprehensive assessment of the yield and nutritional content of a traditional Lacandon Maya milpa. Food Security, 11, 389-404.
Gupta, S., Vemireddy, V., \& Pingali, P. L. (2019). Nutritional outcomes of empowerment and market integration for women in rural India. Food Security, 11, 1243-1256.

Koh, K., Reno, R., \& Hyder, A. (2019). Examining disparities in food accessibility among households in Columbus, Ohio: An agent-based model. Food Security, 11, 317-331.

Lamidi, E. O. (2019). Household composition and experiences of food insecurity in Nigeria: The role of social capital, education, and time use. Food Security, 11, 201-218.

Sileshi, M., Kadigi, R., Mutabazi, K., \& Sieber, S. (2019). Impact of soil and water conservation practices on household vulnerability to food insecurity in eastern Ethiopia: Endogenous switching regression and propensity score matching approach. Food Security, 11, 797-815.

Souissi, A., Mtimet, N., Thabet, C., Stambouli, T., \& Chebil, A. (2019). Impact of food consumption on water footprint and food security in Tunisia. Food Security, 11, 989-1008.

Wang, K., \& Bishop, N. J. (2019). Social support and monetary resources as protective factors against food insecurity among older Americans: Findings from a health and retirement study. Food Security, 11, 929-939.

Willett, W., Rockström, J., Loken, B., Springmann, M., Lang, T., Vermeulen, S., Garnett, T., Tilman, D., DeClerck, F., Wood, A., \& Jonell, M. (2019). Food in the Anthropocene: The EAT-lancet commission on healthy diets from sustainable food systems. The Lancet, 393, 447-492. 